\title{
Generation of Monospecific Peptide Antibodies to the DNA Binding Domain of p53
}

BioTechniques 29:1100-1106 (November 2000)

\author{
K. Huppi, D. Henderson, D. \\ Siwarski, J. Hochman ${ }^{1}$, M. \\ Bergel and G. Tuchscherer ${ }^{2}$ \\ National Cancer Institute, NIH, \\ Bethesda, MD, USA \\ ${ }^{1}$ The Hebrew University of \\ Jerusalem, Jerusalem, Israel \\ ${ }^{2}$ University of Lausanne, \\ Lausanne, Switzerland
}

\begin{abstract}
The DNA binding domain (DBD) is the most mutated region of $p 53$ in tumors and has proven to be relatively resistant to the generation of specific antibodies. Template assembled synthetic peptide (TASP) synthesis of a peptide derived from the DBD creates a highly immunogenic molecule without the need for large carriers such as keyhole limpet hemocyanin (KLH). In addition, a rapid means of generating monoclonal antibodies can be achieved through immunization in conjunction with $A B L /$ $M Y C$ retrovirus injection into recipient mice. In this paper, we demonstrate that an antibody generated by this means, $\mathrm{KH} 2$, reacts specifically with the DBD of p53. To date, this is the first example of a peptide immunogen used successfully in ABL/MYC monoclonal antibody production. KH2 is also the first example of a monospecific antibody that directly binds to and, by definition, assumes the conformation of the DNA binding region of $p 53$.
\end{abstract}

\section{INTRODUCTION}

The tumor suppressor, p53, is one of the most frequently mutated genes in cancer (10), and, in fact, it was the original observation that antibodies to p53 were often found in patients with a wide range of tumors $(4,6)$ that first indicated p53 might be associated with many different types of cancer. Expectedly, the presence of p53 antibodies appears to correlate well with the acquisition of p53 mutations, as $30 \%-40 \%$ of patients carrying a mutant p53 have been found to develop p53 antibodies (14). While it may not be the first step in tumor progression, mutation of $\mathrm{p} 53$ appears to be an important component of the tumorigenic pathway because p53 mutations correlate well with more advanced stages of malignancy and lower overall rates of survival (1). As a negative regulator of cell growth in response to DNA damage, p53 has long been thought to be indispensable to the survival of the cell. Paradoxically, removing p53 function in p53 knockout mice does not result in embryonic lethality, thereby hinting at some functional redundancy that must exist in p53 family members (7). Indeed, the discovery of two additional members of the p53 family, p73 (11) and p51/Ket $(17,20)$, representing two plausible replacements for p53 activity as a com parison of p53, p73 and p51 sequences, reveals substantial amino acid and structural homology.

Since p53 is so often found mutated in tumors and particularly in the most malignant subtypes, the concept of im munizing with mutant p53 to induce an immune response and eventual tumor rejection holds great therapeutic poten- tial (18). However, most p53 antibodies available today bind strictly to the immunodominant $\mathrm{N}$ - or C-terminal regions $(12,19)$. Since these regions reside outside the DNA binding domain (DBD), they rarely acquire mutations to p53, and predictably, most p53 antibodies will not distinguish between wild-type and mutant p53. A rare and extremely valuable exception has been pAB240, which was derived originally from a denatured p53 (9), but which appears to react with most mutant p53 molecules. Following the elucidation of the crystal structure of p53 (5), an explanation for the broad reactivity of pAB240 was that a mutant conformation is unfolded, exposing the normally hidden pAB240 epitope (2). A subtle and important distinction is that pAB240 does not actually bind to the DNA binding region of p53 but binds as a "pocket" antibody to the conformation presented by the surrounding region. Furthermore, previous attempts at generating peptide-specific antibodies have only succeeded in producing antibodies reactive to various regions surrounding the p53 DNA binding site, again not binding directly within this region (23). Very recently, several small synthetic compounds have been identified that effectively bind to the p53 DBD, thereby stabilizing the conformation of a mutant p53 and slowing tumor growth (8). During the course of exam ining differences between tumorigenic and nontumorigenic variants in a mouse T-cell lymphoma, we have found properties corresponding to malignancy or immunogenicity that could be traced to a $\mathrm{p} 53 \mathrm{R} 246 \mathrm{Q}$ or $\mathrm{G} 242 \mathrm{~S}$ mutation, respectively (3). In this paper, we now report a novel approach to 
generate peptide-specific antibodies to the DBD of p53 by coupling the highly immunogenic template assembled synthetic peptide (TASP) approach of peptide synthesis (15) with the ABL/MYC retroviral/immunization method for generating antigen-specific monoclonal antibodies (24).

\section{MATERIALS AND METHODS}

\section{Peptide Synthesis}

Mutant p53 sequences corresponding to amino acid residues 240-251 were designed to be synthesized as TASP (22) with the following sequences: KH1-MAEAAMGSMNRRPILTIG，KH2-MAEAAMGGMNR-
QPILTIG, wherein both the aminoterminal MAEAA and the carboxy-terminal $G$ are used as spacers. The peptides KH1 and KH2 (Figure 1) were synthesized as mutants for residue 246 (KH1) or residue 242 (KH2). The $4 \alpha$ helix bundles were generated using a convergent strategy with four identical chains ligated via chemoselective ligation (oxime bond formation) to a cyclic template molecule (21). The individual building blocks were synthesized according to the Fmoc strategy on solid phase. After completion of the template sequence T:c $[K K(S) G P K(S) K K(S)-$ $\mathrm{GPK}(\mathrm{S})]$, the four serine residues attached to the $\varepsilon \mathrm{NH} 2$ groups of the lysines were oxidized with $\mathrm{NaIO} 4$ to the aldehyde. The two helix sequences ( $\alpha 1$ and $\alpha 2$ ), each carrying an amino- oxy acetyl function at the $\mathrm{N}$ terminus, were reacted in aqueous sodium acetate buffer selectively with the aldehyde groups of the template to yield the two 4 helix bundle TASP molecules KH1 and $\mathrm{KH} 2$, respectively (16). The final products were purified by RP-HPLC and characterized by analytical HPLC and Echelle Spectrograph Spectrograph and Imager (ESI) mass spectroscopy.

\section{Immunization and the Generation of a Monospecific Antibody}

Two- to three-month-old BALB/c mice were immunized with the KH1 or KH2 TASP conjugates resuspended in PBS followed by a boost 14 days later. Mice were infected with ABL/MYC on day 21 following the first immunization

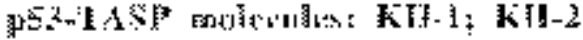
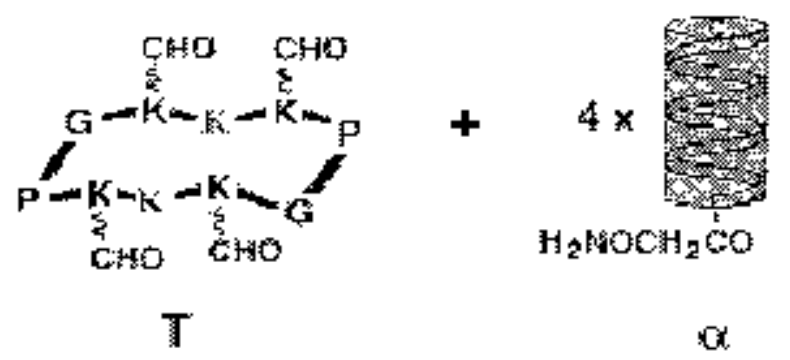

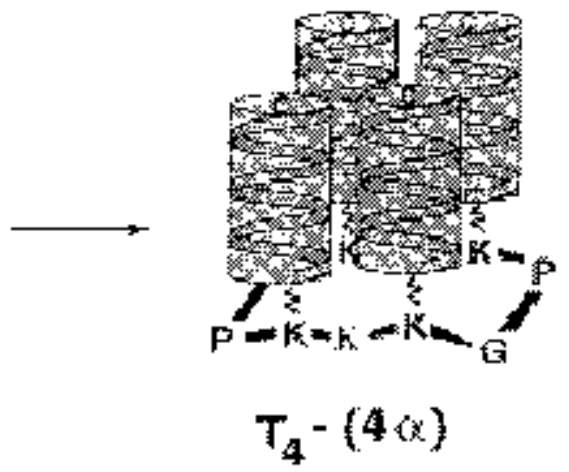

 \\ $y=\quad$ at?

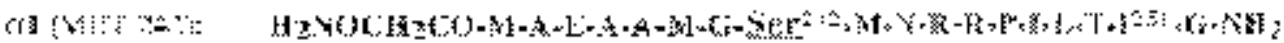

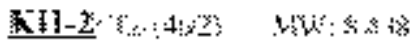

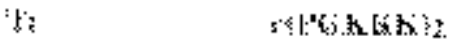

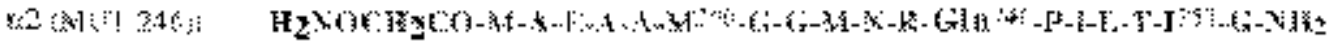

Figure 1. Synthesis of KH1 and KH2 peptides. Both KH1 And KH2 were synthesized as identical $4 \alpha$ helical bundles $(\alpha)$ ligated to a cyclic template molecule (T). Sequences for KH1 And KH2 are shown below along with the molecular weights for each. 
(24). Positive tumors were found in two mice for $\mathrm{KH} 1$ and in four mice for $\mathrm{KH} 2$ at 30 days postimmunization, which were labeled $1 \mathrm{KH} 1,2 \mathrm{KH} 1,1 \mathrm{KH} 2$, $2 \mathrm{KH} 2,3 \mathrm{KH} 2$ and $4 \mathrm{KH} 2$. Crude ascites from each positive tumor were assayed for activity against lysates prepared from the T-cell lines T-60 and T-25 Adh, derivatives of the S49 T-cell lym phoma. Nearly all plasmacytomas induced by conventional methods including mineral oil, pristane, $v$-abl plus pristane, $\mathrm{E} \mu-\mathrm{cMyc} / \mathrm{v}-\mathrm{Hras}, \mathrm{v}-\mathrm{myc} / \mathrm{v}-\mathrm{raf}$ and the ABL/MYC technique used here routinely generate only one antibody expressing a single Ig light chain and heavy chain. While it is unlikely, it is nevertheless conceivable that the original antibody could possibly be oligoclonal. Therefore, $3 \mathrm{KH} 2$ was transplanted by subcutaneous injection of tumor cells into syngenic mice, a method used successfully in a vast number of plasmacytomas for conversion from solid tumor to ascites (18). In the current study, g1, g2 and g3 tumors were generated, which were shown to be monoclonal by specific reactivity to IgG only (as opposed to IgM, IgA, etc.). Monoclonality was further confirmed by Southern blot analysis of Ig light chain and heavy chain genes. Genomic DNA was isolated from $\mathrm{KH} 2 \mathrm{~g} 3$ and from other plasmacytomas induced by mineral oil alone (MOPC265 in Figure 2, lane 3), digested with EcoRI, $B a w H I$ or HindIII restriction enzymes and were hybridized to $\mathrm{IgJ} \kappa, \operatorname{IgC\kappa }$, $\operatorname{IgC} \lambda$ and $\mathrm{IgJh}$ region probes following size separation and transfer to nylon filters. Upon examination for specific monoclonal rearrangements of the antibody genes, the expected germline EcoRI band of $6.6 \mathrm{~kb}$ and two IgJh rearrangements are evident in $\mathrm{KH} 2$ (designated "b" at $2.5 \mathrm{~kb}$ and designated "a" at $5.0 \mathrm{~kb}$ (in Figure 2, lane 2). Typically, a nonproductive IgJh allele can often be found in concert with the productive IgJh allele when assaying Ig rearrangements, and we are confident this is the case with $\mathrm{KH} 2$, as there appears to be only a single Ig $\mathrm{K}$ light chain rearrangement (data not shown).

\section{Immunoprecipitation and Western Assays}

Suspension cells from the T-cell lymphoma, T-60 (mutant at $\mathrm{p} 53$ residue 246), a variant of the T-60 lymphoma, T-25 Adh (an immunogenic T-cell lymphoma mutant at p53 residue 242), T1198 (a mouse plasmacytoma wildtype for p53), T1165 (mouse plasmacytoma wild-type for p53), Wilson (human Burkitt's lymphoma wild-type for p53) and Keeper (human Burkitt's lym phoma mutant for $\mathrm{p} 53, \mathrm{R} 248 \mathrm{Q}$ ) were disrupted by polytron followed by 1 $\mathrm{mM}$ PMSF treatment and centrifugation $(15000 \times g)$ to make lysate preparations. For Western blotting, approximately $40-60 \mu \mathrm{g}$ whole cell lysate were heated at $100^{\circ} \mathrm{C}$, subjected to PAGE and then transferred to nitrocellulose filters by electroblotting. Nonspecific binding was blocked by pre-incubating in $5 \%$ milk/TBS for $1 \mathrm{~h}$ at room temperature. The primary antibodies, $\mathrm{KH} 2$, p53 (Pab 246; Santa Cruz Biotechnology, Santa Cruz, CA, USA), p73 (C-20; Santa Cruz Biotechnology) or p51/Ket (R-20; Santa Cruz Biotechnology) were incubated overnight followed by three washes in TBS plus $0.01 \%$ Tween ${ }^{\circledR} 20$. Incubation for $1 \mathrm{~h}$ at room temperature with the secondary antibody (goat antimouse IgG) conjugated to horseradish peroxidase was followed by three washes as before. The membrane was then incubated in the chemiluminescence luminol reagent for visualization $\left(\mathrm{ECL}^{\circledR}\right.$; Amersham Pharmacia Biotech, Piscataway, NJ, USA).

In the preparation of lysates for im munoprecipitation, cells $\left(10^{8}\right)$ from a suspension culture of ABPC20 (a mouse plasmacytoma wild-type for p53) were resuspended in a lysis buffer consisting of $10 \mathrm{mM}$ Tris-HCl, $\mathrm{pH} 7.5$, 0.5 mM EDTA, pH 8.0, 0.5 mM EGTA, $1.2 \%$ Triton ${ }^{\circledR} \mathrm{X}-100,1 \mathrm{mM}$ PMSF and $1 \mu \mathrm{g} / \mathrm{mL}$ leupeptin. An appropriate dilution of the $\mathrm{KH} 2$ antibody was added to $1 \mathrm{~mL}$ lysate and incubated at $4^{\circ} \mathrm{C}$ overnight. Following a $2-3 \mathrm{~h}$ incubation at $4^{\circ} \mathrm{C}$ with a $50-\mu \mathrm{L}$ mixture of protein A (Sigma, St. Louis, MO, USA) and protein $G$ agarose (Life Technologies, Rockville, MD, USA), the agarose beads were washed extensively with PBS.

For Western analysis after immunoprecipitation, the samples were resuspended in loading buffer, boiled (5 min) and size separated by PAGE $(10 \%)$. Following electrophoresis, pro- teins were electrophoretically transferred to nitrocellulose followed by pre-incubation in TBS (with 5\% milk) for $1 \mathrm{~h}$ at room temperature. The primary antibodies, KH2 or Pab246 (Santa Cruz Biotechnology), were incubated overnight followed by washes in TBS plus $0.01 \%$ Tween $20(3 \times)$. The secondary antibody (sheep antimouse $\mathrm{IgG}$; Amersham Pharmacia Biotech) conjugated to horseradish peroxidase was incubated for $1 \mathrm{~h}$ at room temperature followed by three washes as before. The membrane was then incubated in the ECL for visualization as before.

\section{RESULTS}

\section{Peptide Immunization}

To generate a highly effective monospecific antibody to the DNA binding region of $\mathrm{p} 53$, we have combined two novel protocols, TASP synthesis (15) and $\mathrm{ABL} / \mathrm{MYC}$ retroviral induction of plasmacytomas (24). The rationale behind this two-tiered approach was to



Figure 2. Southern blot analysis of IgH gene rearrangement in plasmacytomas. Approximately $10 \mu \mathrm{g}$ genomic DNA from BALB/c liver (lane 1) and the plasmacytomas KH2 g3 (lane 2) and MOPC265 (lane 3) were digested with EcoRI, gel electrophoresed in $0.7 \%$ agarose and hybridized to radiolabeled probes from the IgH (pJ11) following transfer to nylon membranes. The germline (nonrearranged) band at $6.6 \mathrm{~kb}$ is indicated (solid bar) as are the specific rearranged bands (arrows). 
couple the generation of a highly im munogenic (and soluble) peptide that could be used in the absence of carrier (which often interferes with reactivity to small peptides) with an efficient method of generating monoclonal antibodies via immunization/retroviral injection of mice. As described in Materials and Methods, $20 \mathrm{BALB} / \mathrm{c}$ mice were injected with highly purified preparations of peptides specific to the DNA binding region but mutant for $\mathrm{p} 53$ at residues 242 (KH1) or $246(\mathrm{KH} 2)$. From the initial immunization/retroviral protocol, we obtained tumors (two from $\mathrm{KH} 1$ and four from $\mathrm{KH} 2$ ) for which crude ascites was tested for reactivity to the T-60 (246-Q) or T-25Adh (242-S). All antibodies appeared to react to the same-sized band of $53 \mathrm{kDa}$, with the exception of $4 \mathrm{KH} 2$, which also reacted to a larger species and was probably oligoclonal. From this initial study, the most highly reactive antibody, $3 \mathrm{KH} 2$, was selected for further

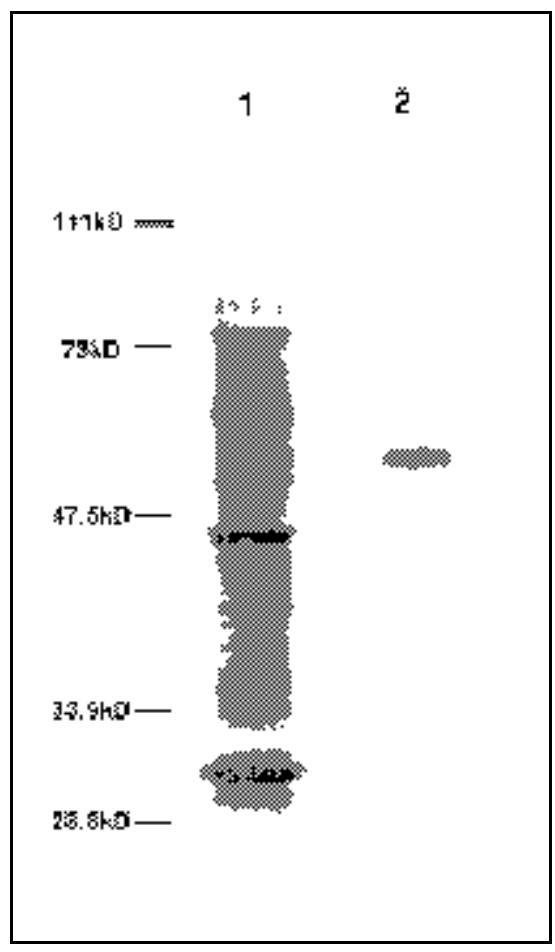

Figure 3. Immunoprecipitation/Western blot of KH2. A cell lysate from the mouse plasmacytoma ABPC20 was immunoprecipitated as described using the $\mathrm{KH} 2$ antibody followed by a mixture of protein A-agarose (Sigma) and protein G-agarose (Life Technologies) (lane 1). The filter of lane 1 was re-incubated with anti-KH2 (primary $\mathrm{Ab}$ ) followed by sheep antimouse as the secondary $\mathrm{Ab}$ (lane 2). The resultant signal is $53 \mathrm{kDa}$ in size. specificity studies and will be referred to as $\mathrm{KH} 2$. As described in Materials and Methods, monoclonality was confirmed by isotype-specific reactivity to $\mathrm{IgG}$ and by direct Southern analysis of genomic DNA isolated from $\mathrm{KH} 2$ ascites cells (Figure 2).

\section{Reactivity Pattern and Specificity of the KH2 Antibody}

Specificity of the KH2 antibody was rigorously tested first by immunoprecipitation and then by Western blotting. In our initial immunoprecipitation experiments with $\mathrm{KH} 2$ on a mouse cell lysate (ABPC20, wild-type for p53), a number of bands including at least 3-7 visible bands by Commassie ${ }^{\circledR}$ stain between the 47.5- and 73-kDa markers were observed (Figure 3 ). To elucidate which bands reacted with $\mathrm{KH} 2$, we turned to Western transfer and blotting of the filters. When the filters in Figure 3 (left panel) were re-incubated with the $\mathrm{KH} 2$ antibody, followed by sheep antimouse secondary antibody, a single distinct band of $53 \mathrm{kDa}$ was observed (Figure 3, right panel).

As the size of the band recognized by $\mathrm{KH} 2$ was $53 \mathrm{kDa}$ in size, we made a direct comparison of the size of the band generated by $\mathrm{KH} 2$ to that of the commercially available p53 antibody, Pab246. In this experiment, the $\mathrm{KH} 2$ antibody was used for the initial im munoprecipitation, the samples transferred to nitrocellulose membranes, separated and finally incubated with anti-KH2 (Figure 4, lane 1) or anti-p53 (Pab246) (Figure 4, lane 2). Clearly, a distinct $53-\mathrm{kDa}$ band reacted to both $\mathrm{KH} 2$ and p53. We also tested the specificity of $\mathrm{KH} 2$ against other members of the p53 family, including p73 and Ket, by combining immunoprecipitation with Western blotting. Repeating the $\mathrm{KH} 2$ immunoprecipitation followed by specific incubation with Ket or p73 antibodies showed no cross-reactivity, whereas $\mathrm{KH} 2$ or $\mathrm{p} 53$ antibodies reacted to a 53-kDa band as expected (data not shown). We also tested $\mathrm{KH} 2$ for reactivity to mutant or wild-type p53 as well as across species boundaries (i.e., mouse or human p53). In Western analysis, $\mathrm{KH} 2$ reacts exclusively with a single band of $53 \mathrm{kDa}$ in both human and mouse lysates (Figure 5). 


\section{Research Report}

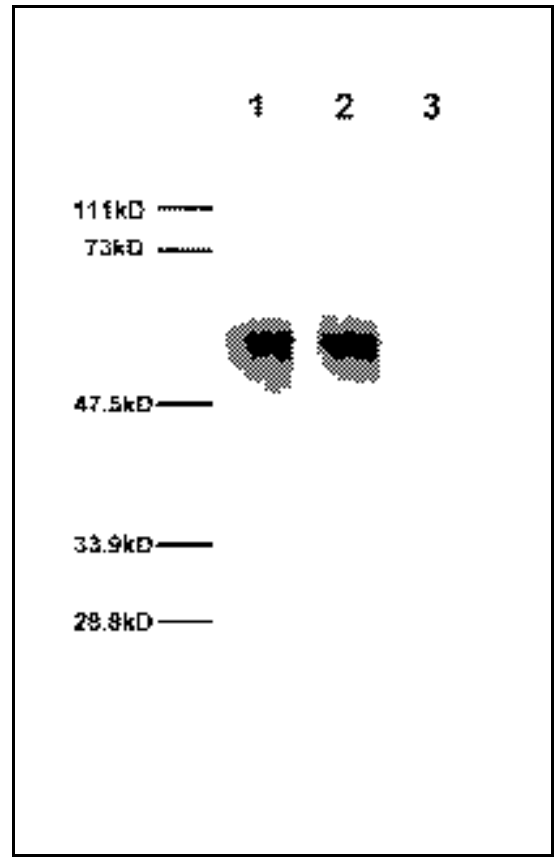

Figure 4. Immunoprecipitation/Western blot comparison of $\mathrm{KH} 2$ versus p53. Cell lysates from the plasmacytoma ABPC20 were immunoprecipitated initially with $\mathrm{KH} 2$ antibody followed by protein $\mathrm{A}$ and protein $\mathrm{G}$ agarose. Precipitates were then denatured by heat shock $\left(98^{\circ} \mathrm{C}, 5 \mathrm{~min}\right)$ and subjected to PAGE. Following electrophoretic transfer, the filters were cut and treated as follows: lane 1, treated with $\mathrm{KH} 2$ (primary $\mathrm{Ab}$ ) followed by sheep antimouse (secondary $\mathrm{Ab}$ ); lane 2, treated with Pab246 (anti-p53 primary Ab) followed by sheep antimouse (secondary Ab); lane 3 , treated only with secondary sheep antimouse $\mathrm{Ab}$ as a control.

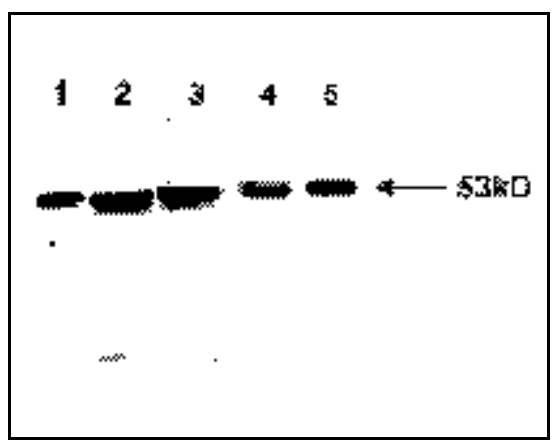

Figure 5. KH2 recognizes human p53 as well as wild-type or mutant mouse p53. Cell lysates were loaded onto PAGE as follows: lane 1, T-25Adh; lane 2, Wilson; lane 3, Keeper; lane 4, TEPC1198 and lane 5, 70Z. For all samples, attempts were made to load similar amounts of protein. Following PAGE and transfer to nitrocellulose membranes, the samples were incubated in the presence of $\mathrm{KH} 2$ antibody (primary) followed by secondary antibody (antimouse IgG) coupled to horseradish peroxidase. Indicated is the size $(53 \mathrm{kDa})$ of the $\mathrm{KH} 2$ reacting protein.

\section{DISCUSSION}

Previously, we had found that mutations in two distinct residues of mouse p53 confer vastly different phenotypic properties with regard to tumor malignancy and immunogenicity in a T-cell lymphoma. An R246Q substitution resulted in a highly malignant phenotype, whereas a G242S substitution appears to rescue this phenotype in an apparent gain of immunogenicity (3). Interestingly, the X-ray crystal structure of p53 offers an explanation as to how glycine at codon 242 might be particularly important to the structure of p53 (5). The L3 loop of p53 does not favor a side chain in the amino acid encoded at residue 242 (the equivalent residue to mouse 242 in human p53 is codon 245), while glycine permits a favorable conformation. Furthermore, the backbone carbonyl of glycine at residue 242 forms a hydrogen bond with an arginine at residue 246 . It is quite likely, therefore, that residues 242 and 246 may be conformationally linked, and thus it may not be coincidental that residues 242 and 246 are the mouse equivalents to two of the most frequently mutated p53 residues in human cancer [i.e., residues $245(6.0 \%)$ and 248 (9.6\%), respectively]. These residues are also centrally located in the DNA binding region of $\mathrm{p} 53$, which has been essentially resistant to the generation of specific antibodies. Despite efforts to generate monoclonal antibodies that recognize mutant $\mathrm{p} 53$, past immunizations with full-length p53 have consistently generated monoclonal antibodies that were reactive to the $\mathrm{N}$ - and $\mathrm{C}$-terminal regions of p53 $(13,19,23)$, and even removal of these classic binding sites from the immunogen has failed to yield antibodies specific to the p53 DBD. From the region in which we generated the $\mathrm{KH} 2$ peptide, we find an extraordinary conservation of amino acids (Figure 6), suggesting that the conformation as presented by the be similar. We might have further predicted that antibodies rendered against a peptide from this region might recognize all three proteins, but this seems not to be the case.

By utilizing a novel technique of placing multiple peptides on a single template, we eliminated the need to use large carriers such as keyhole limpet hemocyanin $(\mathrm{KLH})$, which frequently interfere with the specificity of the antibodies generated by conventional antipeptide modalities. We have combined the TASP synthesis with a method of generating monoclonal antibodies using the ABL/MYC system, which bypasses the need to use rabbits for immunization. A distinct advantage of the ABL/MYC system over hybridoma technology is that far less screening is necessary to identify monospecific antibodies to the immunogen. In the current study, $5 / 6(83.3 \%)$ of the antipeptide antibodies generated by this technique show reactivity to p53 (with the $\mathrm{KH} 2$ antibody exhibiting the greatest reactivity). Previous studies have successfully generated antibodies to lysozyme as well as $\mathrm{SRBCs}$ with high efficiencies of $11 / 13$ and $25 / 32$, respectively (24). One caveat is that, while it is clear that in the current studies $\mathrm{KH} 2$ reacts to the core of the wild-type p53 DBD, KH2 also reacts to T-25-Adh, which carries only a mutant p53 (3). Thus, KH2 will not distinguish between wild-type and mutant p53 (Figure 5).

Mutations in $\mathrm{p} 53$ have been found to DBDs of p53, p73 and p51/Ket might

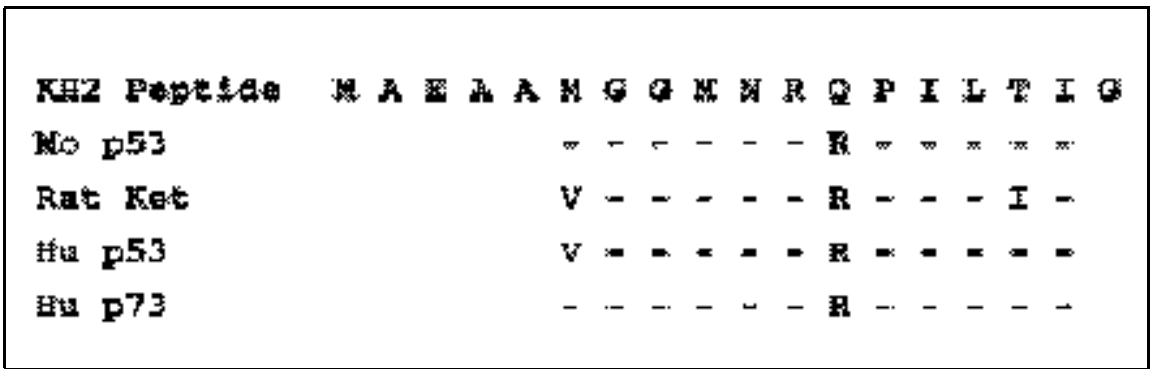

Figure 6. Sequence comparisons with the KH2 peptide. The KH2 peptide sequence is shown above and in comparison to the same region from rat p51/Ket, mouse p53, human p53 and human p73. Identity is depicted by a dash. 
reduce the thermodynamic stability of the DBD, thereby interrupting the function of p53 as a tumor suppressor and transcriptional regulator. To promote the activity of mutant p53, attempts have been directed towards stabilizing the DBD through physical interaction with antibodies or alternative compounds. While no antibodies have been found to date that react to the DBD, compounds have recently been identified that regenerate an active mutant p53 by assuming the conformation of the DBD (24). The unlimited availability of compounds makes this approach invaluable and restricted only by the necessity to screen extremely large numbers of compounds to improve potency and ensure universal reactivity to all mutations. We would suggest that an antibody such as KH2 could be a useful intermediate in screening large numbers of compounds, as $\mathrm{KH} 2$ clearly assumes the conformation of the DBD of p53. Hence, anti-idiotypic antibodies to $\mathrm{KH} 2$ would react to the precise confor- mation assumed by the compounds desired and thereby assist in the selection of the most potent compounds capable of stabilizing p53.

\section{REFERENCES}

1.Aas, T., A.-L. Borresen, S. Geisler, B. SmithSorensen, H. Johnsen, J.E. Vargaug, L.A. Akslen and P.E. Lonning. 1996. Specific p53 mutations are associated with de novo resistance to doxorubicin in breast cancer patients. Nat. Med. 2:811-814.

2.Arrowsmith, C.H. and P. Morin. 1996. New insights into p53 function from structural studies. Oncogene 12:1379-1385.

3.Bergel, M., K. Bhatia, D. Siwarski, M. Gutierrez, J. Hochman and K. Huppi. 1993. Association of tumorigenic and nontumorigenic (immunogenic) variants in a mouse Tcell lymphoma with two distinct p53 mutations. Mol. Carcinogenesis 8:221-227.

4.Caron De Fromental, L.V., F. May-Levin, H. Mouriesse, J. Lemerle, K. Chandrasekaran and P. May. 1987. Presence of circulating antibodies against cellular protein p53 in a notable proportion of children with B-cell lym phoma. Int. J. Cancer 39:185-189.

5.Cho, Y., S. Gorina, P.D. Jeffrey and N.P. Pavletich. 1994. Crystal structure of a p53 tumor suppressor-DNA complex: understanding tumorigenic mutations. Science 265:346-355.

6.Crawford, L.V., D.C. Pim and R.D. Bulbrook. 1982. Detection of antibodies against the cellular protein p53 in sera from patients with breast cancer. Int. J. Cancer 30:403-408.

7.Donehower, L.A., M. Harvey, B.L. Slagle, M.J. McArthur, C.A. Montgomery, Jr., J.S. Butel and A. Bradley. 1992. Mice deficient for p53 are developmentally normal but susceptible to spontaneous tumors. Nature 356:215-221.

8.Foster, B.A., H.A. Coffey, M.J. Morin and F. Rastinejad. 1999. Pharmacological rescue of mutant p53 conformation and function. Science 286:2507-2510.

9.Gannon, J.V., R. Greaves, R. Iggo and D.P. Lane. 1990. Activating mutations in p53 produce a common conformational effect. A monoclonal antibody specific for the most comon mutant form. EMBO J. 9:1595-1602.

10.Hollstein, M., K. Rice, M.S. Greenblatt, T. Soussi, R. Fuchs, T. Sorlie, E. Hovig, B. Smith-Sorensen, R. Montesano and C.C. Harris. 1994. Database of p53 gene somatic mutations in human tumors and cell lines. $\mathrm{Nu}-$ cleic Acids Res. 22:3551-3555.

11.Kaghad, M., H. Bonnet, A. Yang, L. Creancier, J.-C. Biscan, A. Valent, A. Minty, P. Chalon et al. 1997. Monoallelically expressed gene related to $\mathrm{p} 53$ at $1 \mathrm{p} 36$, a region frequently deleted in neuroblastoma and other human cancers. Cell 90:809-819.

12.Labrecque, S., N. Naor, D. Thomson and G. Matlashewski. 1993. Analysis of the anti-p53 antibody antibody response in cancer patients. Cancer Res. 53:3468-3471.

13.Legros, Y., C. Lafon and T. Soussi. 1994. Mutations in $\mathrm{p} 53$ produce a common conformational effect that can be detected with a pan- el of monoclonal antibodies directed towards the central part of the p53 protein. Oncogene 9:2071-2076

14.Lubin, R., B. Schlichtholz, J.L. Teillaud, E. Garay, A. Bussel, C.P. Wild and T. Soussi. 1995. p53 antibodies in patients with various types of cancer: assay, identification and characterization. Clin. Cancer Res. 1:1463-1469.

15.Mutter, M. 1988. Nature's rules and chemist's tools: a way of creating novel proteins. Trends Biochem. Sci. 13:261-265.

16.Nyanguile, O., M. Mutter and G. Tuchscherer. 1994. Synthesis of antiparallel 4a-helix bundle TASP by chemoselective ligation. Lett. Pept. Sci. 1:9-16.

17. Osada, M., M. Ohba, C. Kawhara, C. Ishioka, R. Kanamaru, I. Katoh, Y. Ikawa, Y. Nimura et al. 1998. Cloning and functional analysis of human $\mathrm{p} 51$, which structurally and functionally resembles p53. Nat. Med. 4:839843.

18.Potter, M. 1967. The plasma cell tumors and myeloma proteins of mice. Methods Cancer Res. 2:105-157.

19.Schlichtholz, B., Y. Legros, D. Gillet, C. Gaillard, M. Marty, D. Lane, F. Calvo and T. Soussi. 1992. The immune response to p53 in breast cancer patients is directed against im munodominant epitopes unrelated to the mutational hotspot. Cancer Res. 52:6380-6384.

20.Schmale, H. and C. Bamberger. 1997. A novel protein with strong homology to the tumor suppressor p53. Oncogene 15:1363-1367.

21.Tuchscherer, G. 1993. Template assembled synthetic proteins: condensation of a multifunctional peptide to a topological template via chemoselective ligation. Tetrahedron Lett. 34:8419-8422.

22.Tuchscherer, G., C. Servis, G. Corradin, U. Blum, J. Rivier and M. Mutter. 1992. Total chemical synthesis, characterization, and im munological properties of an MHC class I model using the TASP concept for protein de novo design. Prot. Sci. 1:1377-1386.

23. Vojtesek, B., H. Dolezalova, L. Lauerova, M. Svitakova, P. Havlis, J. Kovarik, C.A. Midgley and D.P. Lane. 1995. Conformational changes in p53 analysed using new antibodies to the core DBD of the protein. Oncogene 10:389-393.

24. Weissinger, E.M., H. Mischak, D.A. Largaespada, D.A. Kaehler, T. Mitchell, S.J. SmithGill, R. Risser and J.F. Mushinski. 1991. Induction of plasmacytomas secreting antigen-specific monoclonal antibodies with a retrovirus expressing v-abl and c-myc. Proc. Natl. Acad. Sci. USA 88:8735-8739.

Received 14 February 2000; accepted 5 July 2000.

Address correspondence to:

Dr. Konrad Huppi

Laboratory of Genetics

National Cancer Institute

National Institutes of Health

Building 37, Room 2B-21

Bethesda, MD 20892, USA

e-mail:huppi@helix.nih.gov 